\title{
DEVELOPMENT AND FEASIBILITY OF A WASTE PACKAGE COUPLED REACTIVE TRANSPORT MODEL (AREST-CT)
}

\author{
D. W. Engel \\ B. P. McGrail \\ J. A. Fort \\ J. S. Roberts \\ $\vdots$
}

May 1994

Presented at the

International High-Level Radioactive Waste Management

Conference

May 22-26, 1994

Las Vegas, Nevada

: Prepared for

the U.S. Department of Energy

under Contract DE-AC06-76RLO 1830

Pacific Northwest Laboratory
Richland, Washington 99352

DISCLAIMER

This report was prepared as an account of work sponsored by an agency of the United States Government. Neither the United States Government nor any agency thereof, nor any of their employees, makes any warranty, express or implied, or assumes any legal liability or responsibility for the accuracy, completeness, or usefulness of any information, apparatus, product, or process disclosed, or represents that its use would not infringe privately owned rights. Reference herein to any specific commercial product, process, or service by trade name, trademark, manufacturer, or otherwise does not necessarily constitute or imply its endorsement, recommendation, or favoring by the United States Government or any agency thereof. The views and opinions of authors expressed herein do not necessarily state or reflect those of the United States Government or any agency thereof.

PNL-SA-23965 


\section{DISCLAIMER}

Portions of this document may be illegible in electronic image products. Images are produced from the best available original document. 


\title{
DEVELOPMENT AND FEASIBILITY OF A WASTE PACKAGE COUPLED REACTIVE TRANSPORT MODEL (AREST-CT)
}

\author{
David W. Engel, B. Pete McGrail, James A. Fort, and Janet S. Roberts \\ Pacific Northwest Laboratory ${ }^{2}$ \\ P.O. Box 999 \\ Richland, Washington 99352
}

(509)375-2307

\section{ABSTRACT}

Most models that analyze the waste package and engineered barrier system (near-field) of an underground geologic repository assume constant boundary conditions at the waste form surface and constant chemical properties of the groundwater. These models are useful for preliminary modeling, iterative modeling to estimate uncertainties, and as a source for a total systems analysis. However, the chemical behavior of the system is a very important factor in the containment and release of radionuclides, and we need to understand the underlying processes involved. Therefore, we are developing a model to couple the calculation of the chemical properties with the reactive transport which can be used to assess the near-field. This report describes the models being implemented and presents some simple analyses demonstrating the feasibility of the chemical and coupled transport models.

\section{INTRODUCTION}

The Analytical REpository Source-Term (AREST) code has been selected by the Department of Energy/Yucca Mountain Site Characterization Project Office (DOE) to be its primary waste package performance assessment (PA) model. ${ }^{1}$ The current version of the AREST code ${ }^{2}$ is based on a series of analytical models ${ }^{3}$ and a simple one-dimensional finite-difference numerical model ${ }^{4}$ for calculating nuclide transport to the host rock of an underground geologic repository. Constant boundary conditions are assumed at the waste form surface, while chemical properties of the groundwater and engineered barrier system (EBS) materials are held fixed.

The analytical models in the AREST code have proven to be extremely useful tools for analyzing waste package performance, and have recently been extended to incorporate a geochemical model for glass waste form dissolution. ${ }^{2}$ However, in the next few years the DOE plans to use the AREST code for detailed analyses of the EBS design, regulatory compliance assessment, and benchmarking against Total Systems Performance Assessment (TSPA) codes. The process models that are currently implemented in the AREST code are inadequate for these functions, in part because of the special unsaturated conditions at the potential site for the repository at Yucca Mountain, Nevada.

It has been shown that the simplified treatment of critical chemical processes affecting containment, radionuclide release, and migration are not adequate for a detailed analysis of the waste package. For example, chemical retardation depends on a variety of solution and solid chemical properties, and a constant retardation factor is known to be inappropriate for modeling solute transport in geologically complex systems. ${ }^{5,6}$ Yet the current version of the AREST code and other PA codes use fixed $\mathrm{K}_{d}$ values that have been demonstrated to give nonconservative breakthrough times by as much as $10^{4}$ years for several key radionuclides. ${ }^{7}$ In our 1992 study, ${ }^{8}$ we demonstrated that chemical changes in groundwater chemistry resulting from glass dissolution can significantly affect the solubilities of key actinide elements.

Thus, the new version of the AREST code will model geochemistry and multicomponent reactive transport internally. For this reason, the new version 'will be called AREST-CT, Analyzer for REpository Source-Term with Chemical Transport.

This report briefly describes the new models being implemented into the AREST-CT code along with some simple analyses comparing run times for calculating the chemistry versus the time to calculate transport of the different elements. These analyses are an attempt to

¿Operated for the U.S. Department of Energy by Battelle Memorial Institute under Contract DE-AC06-76RLO 1830. 
demonstrate the feasibility of using these models for realistic waste package PA problems, and to estimate the, size of problem we can realistically plan on solving.

\section{MODEL DESCRIPTION}

New process models that will use water chemistry parameters are being implemented into the AREST-CT code. The new process models include:

- container and cladding corrosion (uniform, pitting, intergranular attack, and stress corrosion)

- spent fuel dissolution

- glass dissolution.

The container corrosion models will be material specific and will be incorporated as they are developed by the repository program. For example, the models may use predicted concentrations of $\mathrm{Cl}^{-}$or $\mathrm{HS}^{-}$to calculate uniform corrosion rates or to generate probability distributions for a localized failure mechanism like stress corrosion cracking. Dissolution rates of spent fuel and glass waste forms will be directly related to the groundwater chemistry through empirical ${ }^{9}$ or thermodynamic relationships. ${ }^{10}$

The AREST-CT code is designed to solve a set of stiff, highly non-linear partial differential equations (PDE's) that govern the transport, decay, and chemical reactions of multiple chemical species. The code will have capabilities to treat problems with the following characteristics:

\section{Transport}

- multicomponent

- variable saturation

- diffusion and advection

- arbitrarily shaped domains

- time variant and spatially variant transport properties

- time variant (including periodic) and spatially variant boundary conditions

- radioactive decay and decay-chain ingrowth

\section{Chemistry}

- precipitation/dissolution

- aqueous complexation

- oxidation/reduction

- ion-exchange

- adsorption

- isotope partitioning.

Most geochemical models enforce chemical equilibrium constraints. The AREST-CT code, however, will allow the free mixing of kinetic rate-controlled and equilibrium-controlled reactions. Isotope partitioning will also be implemented directly into the chemical model. Isotope partitioning is important to enforce shared solubility and aqueous speciation constraints among 2 or more isotopes.

Nearly all computer codes developed to solve chemical equilibrium problems have implemented the mass action approach..$^{11,12,13}$ However, we have selected the chemical potential approach to solve chemical equilibrium problems in the AREST-CT code. ${ }^{14}$ Convergence of mass action models can depend on the choice of basis species and thus uniqueness of the solution cannot be guaranteed. ${ }^{15}$ With the chemical potential approach, there are no basis species, and thus convergence does not depend on their choice. Also, the chemical potential approach lends itself much more easily to solving a wide variety of chemical equilibrium problems, because the model requires a consistent specification of the chemical potential and the derivative of the chemical potential for each process.

Numerous numerical transport schemes exist for solving the advection-dispersion equations. However, it is well known that some of the numerical techniques for capturing the movement of a steep concentration front tend to exhibit severe oscillation at the front and also display substantial numerical dispersion. ${ }^{16}$ We have examined several different solution algorithms for implementation into the AREST-CT code for solving this type of problem. Figures 1 and 2 show sample calculation results for a test problem where a square wave in tracer concentration is transported in a uniform velocity field. Physical diffusion is set to zero in all cases. These results were produced with three of the spatial differencing schemes in UTCHEM: single point upstream, two point upstream, and third-order TVD. ${ }^{17,18,19}$ Figure 1 illustrates the same scale of problem that was presented by McGrail and Engel, ${ }^{16}$ using 2 nodes to describe the front. Figure 2 represents the results from UTCHEM when using 8 nodes to describe the front. From these results and our investigation of other techniques, we plan to implement a third-order TVD numerical scheme into the AREST-CT code.

\section{ANALYSIS}

Solving chemical equilibrium problems for a system of PDE's that have been discretized in space requires the solution of at least $N_{n} \times N_{s}$ equations at each time step, where $N_{n}$ is the number of nodes and $N_{3}$ is the number of species. Solving the transport equations requires the solution of an additional set of $N_{a} \times N_{e}$ equations, where $N_{c}$ is the number of chemical elements. For a typical problem, however, $N_{e} \ll N_{s}$ so up to $95 \%$ of the 
computational time may be spent solving the chemical reaction equations. ${ }^{20.21}$ Fortunately, each node of the chemical reaction solution will be treated independently, and thus the equation systems lend themselves naturally to advanced computing schemes that use distributed parallel processing.

Simple analyses were run for both the chemical equilibrium solution and the transport solution. These analyses were done separately, with the assumption that a constant number of iterations is required between the chemical and the transport models to ensure that mass balance constraints are satisfied. The analyses were run on a SPARC 10/20 (SPARCStation 10 Model 20 with 32 MBytes main memory, $20 \mathrm{MHz}, 75 \mathrm{MIPS}$, and 15 MFLOPS). The central processing unit (CPU) time was used as the measure of comparison for each analysis, i.e., run.

\section{A. Chemistry}

Analyses were run using the chemical potential approach to solve several batch chemical equilibrium problems. The computer code GMIN was used for these runs. ${ }^{22}$ GMIN comes with a limited built-in database that contains the necessary chemical potential data for aqueous species and mineral phases. Activity coefficients may be calculated using the Davies equation or with the Pitzer ion-pairing method. ${ }^{23}$ Simulations were run using both of these methods to determine differences in the

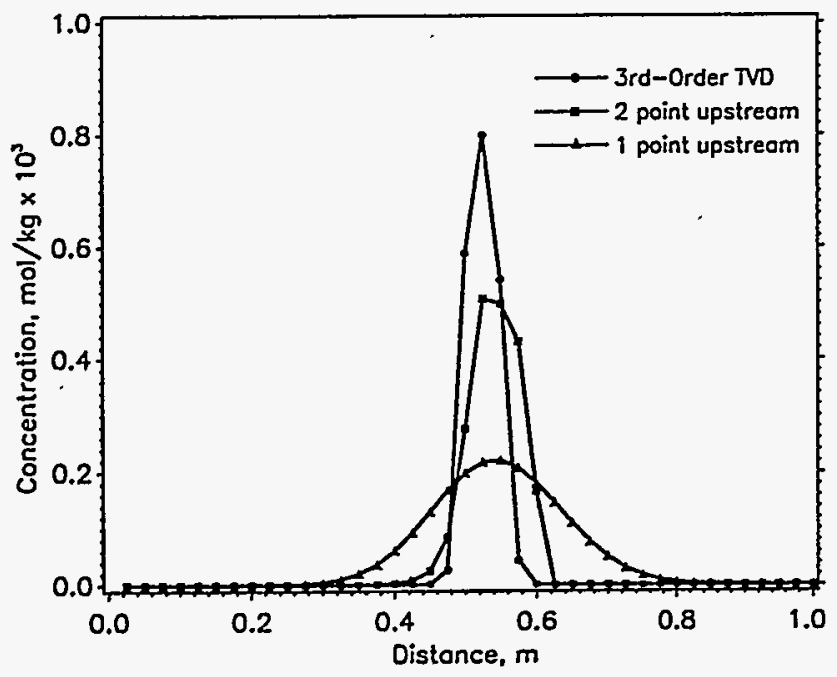

Figure 1. Advective Tracer Test Using UTCHEM and 2 nodes to Describe the Front

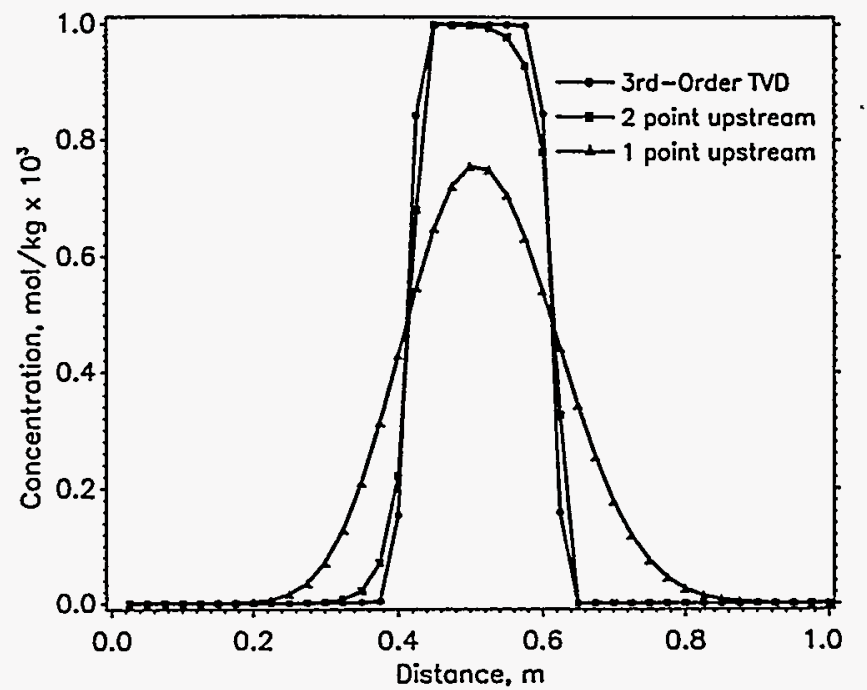

Figure 2. Advective Tracer Test Using UTCHEM and 8 nodes to Describe the Front

computational times required. However, we don't expect to use the Pitzer option for most cases, due to the low ionic strengths for most analyses.

Timing runs were performed starting with only 1 aqueous species, $\mathrm{H}^{+}$. Aqueous species were then added to the problem one at a time and the code run 3 times to determine a statistical average of the CPU time spent to solve the problem. After adding 33 aqueous species, mineral phases were then added one at a time and CPU time required to solve each problem again recorded.

\section{B. Transport}

Several analyses were then run solving the advectiondispersion transport equations. The computer code MSTS was used for these runs..$^{24,25}$ Table 1 lists the data describing the analyses. Separate analyses were run by modifying the grid size, increasing the number of nodes in both the $x$ - and $y$-direction. For these analyses, only a single element was being transported.

The MSTS code uses an implicit Newton-Raphson scheme to solve the numerical transport problem. Because we plan on implementing a third-order TVD scheme into the AREST-CT code, we also compared the computational times from MSTS and from UTCHEM on a onedimensional problem. 


\section{DISCUSSION}

Figure 3 shows the average CPU time required to solve the chemistry equations as a function of the number of aqueous species, for a single node and time step. For these analyses, adding up to 10 mineral phases to the problem had a negligible impact on CPU time required, so no further tests with additional mineral phase constraints were performed. We believe the mineral phase additions had little effect on CPU time because each solid phase acts as a constraint for only a few species, whereas with the Pitzer method, the number of equations to be solved increases rapidly by a complicated combinatorial function related to the number of binary and ternary ion-ion interactions.

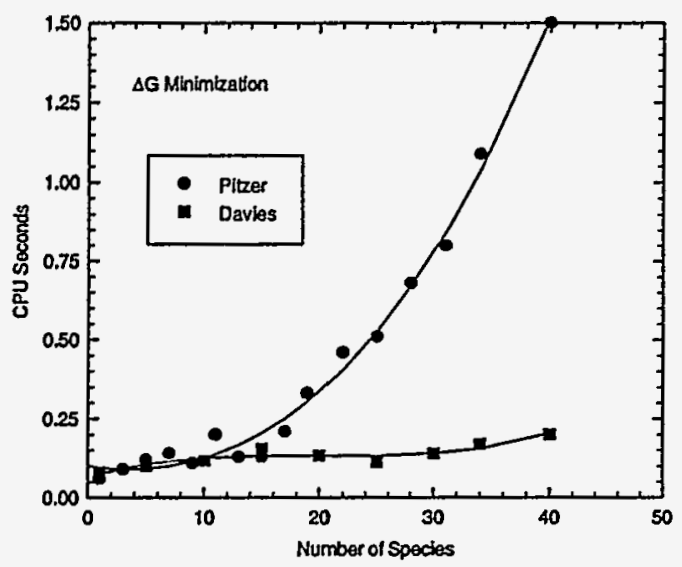

Figure 3. CPU Execution Time as a Function of the Number of Aqueous Species

The total CPU time required for each calculation of the transport model is shown in Figure 4. The data points represent the actual CPU times for the 5 cases, while the curve represents a quadratic fit to the data points. This Figure represents the total CPU time, but does not show the number of time steps $\left(N_{)}\right)$for each run. For example, the 100 node run required 38 time steps to reach 20 days, while the 10,000 node problem needed 123 time steps for the 20 day analysis. The difference in the number of time steps occurs because of the maximum allowable time step $(\Delta t, d)$, that is input into MSTS. The time step was calculated from the Courant number, which was limited by the following relationship: ${ }^{25}$

$$
\mathrm{Cr}=\frac{\mathrm{u} \Delta \mathrm{t}}{\Delta \mathrm{x}} \leq 1
$$

Table 1. Data Description and Cases for the Transport Modeling

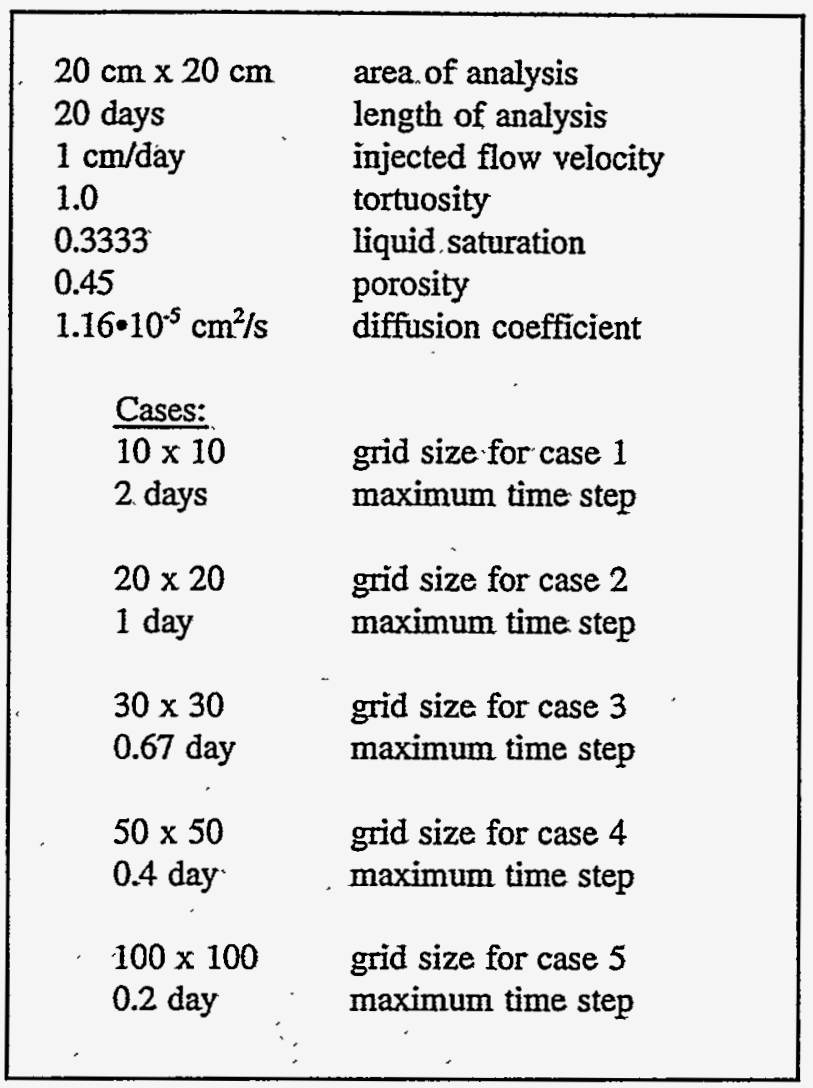

where $\mathrm{Cr}$ is the Courant number, $\mathrm{u}$ is the Darcy velocity $(\mathrm{cm} / \mathrm{d})$, and $\Delta x$ is the grid cell length in the $x$-direction (cm).

Figure 5 represents the average CPU time to calculate transport at each node-time step combination. The actual average CPU time for each calculation is represented by a solid circle, while a linear representation of the relationship between the average CPU time and the number of nodes $\left(N_{n}\right)$ is represented by the solid line, as given below:

$$
\text { CPU(s/node/step) }=2.82 \cdot 10^{-4}+1.37 \cdot 10^{-6} \mathrm{~N}_{\mathrm{n}}
$$

A simple comparison was also made using the Newton-Raphson solution technique and the third-order TVD scheme to solve the same one-dimensional transport problem. The results of the comparison showed about a factor of 4 increase in computational time for the thirdorder TVD scheme.

Using the relationship from Equation 2, we can estimate the amount of time required for similar analyses, i.e., same Courant number, uniform flow field, and similar 
material and environmental properties. For example, to estimate the CPU time to transport a single element defined by a $2 \mathrm{~m}$ by $2 \mathrm{~m}$ area using a $20 \times 20$ uniform grid for 100 years, we apply the Courant number relationship (Equation 1) to get a maximum time step of 10 days (10 $\mathrm{cm} / 1 \mathrm{~cm}$ per day), for a minimum of 3650 time steps (100 yrs/10 days). Thus, it should take about $1,460,000$ calculations ( 3650 steps 400 nodes) for the analysis. From Equation 2, we would estimate about $8.3 \cdot 10^{-4}$ (s/calculation), for an estimated total CPU time of 1212 seconds using a Newton-Raphson scheme (MSTS) or an estimated 4848 seconds using the TVD solution technique (UTCHEM).

The actual analysis for this problem took about 563 CPU seconds to complete, using MSTS and 3685 time steps. The estimate and the actual time for the analysis differ by about a factor of 2 , and the error is on the conservative side, i.e., we over-estimated the time required. Part of the over-estimate can be explained by the setup cost for the different problem scales. The estimated times represented by Equation 2 are the average time for all of the calculations. The time is estimated by taking the total CPU time, including problem setup, and dividing by the number of calculations $\left(N_{t} \times N_{n}\right)$. Thus, for the smaller problems we would expect to over-estimate the actual CPU times.

Using the previous example, we would like to

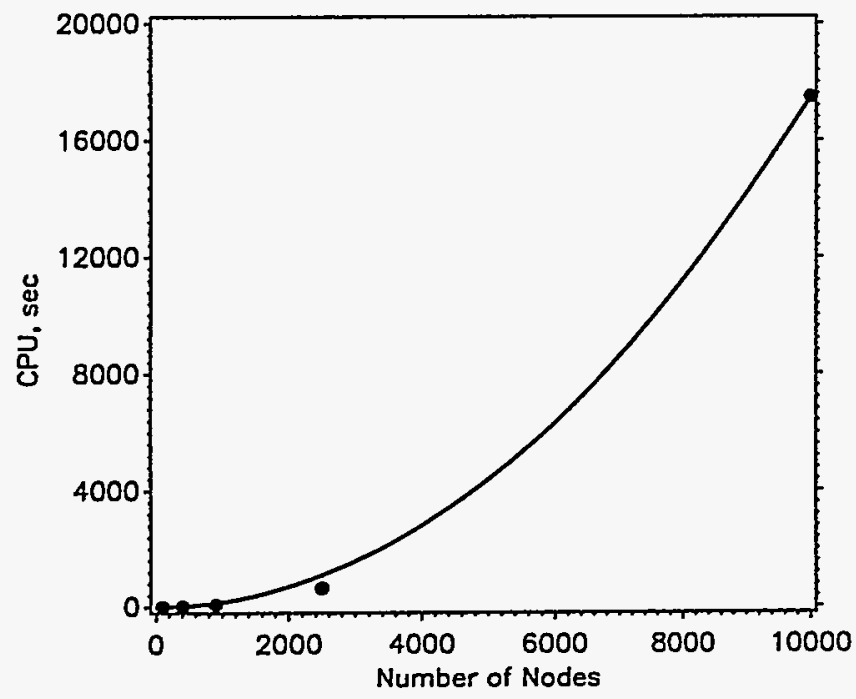

Figure 4. Results From Running the Transport Model, MSTS, Total CPU Time Versus the Number of Nodes

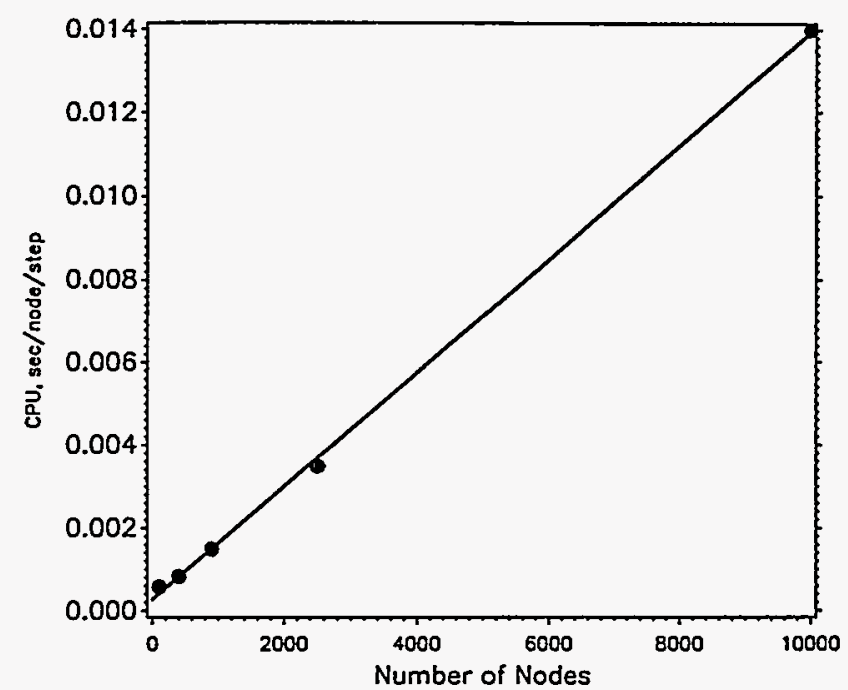

Figure 5. Results From Running the Transport Model (MSTS), Comparing Average CPU Time for Each Calculation (Node and Time step) Versus the Number of Nodes

estimate the time required to solve the chemistry and the transport solution, using the same $20 \times 20$ uniform grid for 100 years. Thus, an estimated total of $1,460,000$ calculations will be needed, assuming that the computational time scales directly with the number of nodes and time steps. From Figure 3, it is estimated to take about $1 \mathrm{CPU}$ second per calculation for the Pitzer option and about 0.2 seconds for the Davies equation if we are interested in 33 species. Therefore, we would estimate a total of $1,460,000$ seconds (16.9 days) using the Pitzer option and 292,000 seconds (3.38 days) using the Davies equation. The estimated time to solve the transport, on the other hand, was only 1212 seconds (20.2 minutes) for a single element. To track 20 elements, the estimated total CPU time for the transport would be 24240 seconds (6.73 hours) using the Newton-Raphson scheme and 96,960 seconds (26.93 hours) using the TVD solution technique.

From the previous example, we see that the chemistry dominates the computational time. Fortunately, with the numerical schemes which are being implemented into the AREST-CT code, we will solve the transport equations independent of the calculations for the geochemistry. The chemistry will be solved a node at a time, with each node being solved independently. Therefore, we should be able to take advantage of distributed parallel processing. 
The transport model is not readily suited to distributed parallel processing, but it will certainly be possible to take advantage of faster computers and advanced numerical algorithms for parallel processing of large problems, e.g., using multi-grid techniques. For example, two of the transport cases were also run on different computers (IBM RS6000, DEC Alpha, and the SPARC). The results of the comparison are shown in Table 2. These results illustrate the importance of the computer speed, architecture, and the compiler options (optimization versus nonoptimization).

For a bigger problem, e.g., 10,000 nodes (100x100) and 10,000 years, the computational time becomes even more significant. For instance, if we assume the solution time and problem set scales linearly with the increased problem size, we would estimate an increase in computational time by a factor of 2,500 (10000 nodes -10000 years $/ 400$ nodes 100 years). However, using the timing runs reported in Table 2, we may decrease the computation time by a factor of 25 by going to a faster workstation. Thus, the estimated factor for the larger problem would be 100 . Therefore, using the Davies equation for the chemistry and a third-order TVD solution technique for the transport, we would estimate a computational time of 450 days (100- 4.5 days).

\section{CONCLUSIONS}

The DOE is planning to use the AREST code to perform detailed analyses of the waste package and EBS of the potential site for the underground repository at Yucca Mountain. The current version of the AREST code, and many other PA codes, use constant boundary conditions at the waste form surface and for the geochemistry. These conditions are not adequate for the detailed modeling that is needed for waste package design, regulatory compliance assessment, and supporting TSPA calculations. Thus, the AREST code is being modified to include coupled geochemical and multicomponent reactive transport, along with the interaction with the container and waste form process models.
For this report, separate chemical and transport modules were analyzed to estimate the computational requirements for the type of models we are implementing into the AREST-CT code. From these results, we extrapolated to estimate the computational time (CPU time) for different size problems. To do this, we estimated the average CPU time required to solve a single calculation, one time step, one species/element, and one node. An estimate was then made for the number of calculations for each problem. Then the total CPU time was estimated by multipling the average CPU per calculation by the estimated number of calculations.

For a small problem it was estimated to take 4.5 days to solve the chemical and coupled transport problem on a typical workstation (SPARC 10/20), or about 4.32 hours on a very fast workstation (DEC Alpha). For a larger, and more realistic PA problem, it was estimated to take 450 days of computational time, on the fast workstation.

From our calculations we saw that the chemical equilibrium calculations dominated the computation time. However, the solution to the chemistry lends itself to advanced computational techniques that reduce the time it takes to solve the coupled chemical and transport equations. Distributed processing, parallel processing, and advanced algorithms for the most efficient use of computer resources will be investigated during the implementation and testing stages of the code development and modification. Each node of the equilibrium chemical calculations, for example, is solved independently of the others, thus becoming a perfect candidate. for distributed parallel processing.

From our analyses and extrapolations, we estimated some very large computation times on todays workstations. However, we can reduce the computational time by going to faster computers, more efficient compilers, and by using advanced computing techniques. Therefore, problems that take days, even months to run today, may run overnight on computers in the next year or two.

Table 2. CPU Time Comparison for Solving Transport Equations on Different Computers

\begin{tabular}{|c|c|c|c|c||}
\hline $\begin{array}{c}\text { Problem } \\
\text { Size }\end{array}$ & $\begin{array}{c}\text { DEC } \\
\text { Alpha DECpc } \\
\text { AXP 150 } \\
(150 \mathrm{MHz})\end{array}$ & $\begin{array}{c}\text { SUN } \\
\text { SPARC } \\
10 / 20 \\
(20 \mathrm{MHz})\end{array}$ & $\begin{array}{c}\text { IBM } \\
\text { RS6000 560 } \\
\text { non-optimized } \\
(45 \mathrm{MHz})\end{array}$ & $\begin{array}{c}\text { IBM } \\
\text { RS6000 560 } \\
\text { optimized } \\
(45 \mathrm{MHz})\end{array}$ \\
\hline \hline $50 \times 50$ & $27 \mathrm{sec}$ & $832 \mathrm{sec}$ & $105 \mathrm{sec}$ & $29 \mathrm{sec}$ \\
\hline $100 \times 100$ & $320 \mathrm{sec}$ & $11,230 \mathrm{sec}$ & $1,232 \mathrm{sec}$ & $300 \mathrm{sec}$ \\
\hline
\end{tabular}




\section{ACKNOWLEDGEMENTS}

The authors would like to thank Frank Ryan and Carrie Savard for their editorial support. Special thanks go to Judi Cuta for her technical review and comments.

\section{REFERNCES}

1. A. Van Luik, D. Stahl, and D. Harrison, "Progress in Waste Package and Engineered Barrier Systems Performance Assessment and Design," Scientific Basis for Nuclear Waste Management XVI, Materials Research Society, Pittsburgh, Pennsylvania (1993).

2. D.W. Engel and B.P. McGrail, AREST Model Description, PNL-8659, Pacific Northwest Laboratory, Richland, Washington (1993).

3. T.H. Pigford, P.L. Chambré, and W.W.-L. Lee, A Review of Near-Field Mass Transfer in Geologic Disposal Systems, LBL-27045, Lawrence Berkeley Laboratory, Berkeley, California (1990).

4. P. Grindrod, M. Williams, and H. Grogan, STRENG: A Source-Term Model for Vitrified High-Level Waste, NAGRA Technical Report, NTB 90-48, Badan, Switzerland (1991).

5. E.J. Reardon, "K's - Can they Be Used to Describe Reversible Ion Sorption Reaction in Contaminant Migration?" Ground Water, 19, 279-286 (1981).

6. R.J. Serne and A.B. Muller, "A Perspective on Adsorption of Radionuclides Onto Geologic Media," The Geological Disposal of High Level Radioactive Wastes, Theophrastus Publications, Athens, Greece . (1987).

7. C. Pescatore and T. Sullivan, "Sorption-Capacity Limited Retardation of Radionuclide Transport in Water-Saturated Packing Material," Scientific Basis for Nuclear Waste Management VIII, Material Research Society, Pittsburgh, Pennsylvania (1985).

8. B.P. McGrail and D.W. Engel, "Coupled Process Modeling and Waste Package Performance," Scientific Basis for Nuclear Waste Management XVI, Material Research Society, Pittsburgh, Pennsylvania (1993).

9. C.N. Wilson, Results from NNWSI Series 3 Spent Fuel Dissolution Tests, PNL-7170, Pacific Northwest Laboratory, Richland, Washington (1990).
10. W.L. Bourcier, D.W. Peiffer, K.G. Knauss, K.D. McKeegan, and D.K. Smith, "A Kinetic Model for Borosilicate Glass Dissolution Based on the Dissolution Affinity of a Surface Alteration Layer," Scientific Basis for Nuclear Waste Management XIII, Materials Research Society, Pittsburgh, Pennsylvania (1989).

11. T.J. Wolery, EQ3NR - A Computer Program for Geochemical Aqueous Speciation-Solubility Calculations: User's Guide and Documentation, UCRL-53414, Lawrence Livermore Laboratory, Livermore, California (1983).

12. D.L. Parkhurst, D.C. Thorstenson, and L.N. Plummer, PHREEQE - A Computer Program for Geochemical Calculations, USGS/WRI-80-96, U.S. Geological Survey, Reston, Virginia (1980).

13. A.R. Felmy, D.C. Girvin, and E.A. Jenne, MINTEQ A Computer Program for Calculating Aqueous Geochemical Equilibria, EPA 600/3-84-032, U.S. Environmental Protection Agency, Office of Research and Development, Athens, Georgia (1984).

14. C.E. Harvie, J.P. Greenberg, and J.H. Weare, "A Chemical Equilibrium Algorithm For Highly Nonideal Multiphase Systems: Free Energy Minimization,". Geochim. Cosmochim. Acta 51, 10451057 (1987).

15. C.M. Bethke, "The Question of Uniqueness in Geochemical Modeling," Geochim. Cosmochim. Acta 56, 4315-4320 (1992).

16. B.P. McGrail and D.W. Engel, "Perspectives on Performance Assessment and High-Level Waste Glass in a Geologic Repository," Scientific Basis for Nuclear Waste Management XVII, Material Research Society, Pittsburgh, Pennsylvania (1994).

17. N. Saad, Field Scale Simulation of Chemical Flooding, Doctoral Dissertation, University of Texas, Austin, Texas (1989).

18. D. Bhayan, Development of an Alkaline/Surfactant/ Polymer Compositional Reservior Simulator, Doctoral Dissertation, University of Texas, Austin, Texas (1989).

19. A.D. Gupta, L.W. Lake, G.A. Pope, K. Sepehrnoori, and M.J. King, "High-Resolution Monotonic Schemes for Reservoir Fluid Flow Simulation," In Situ, 15(3), 289-317 (1991). 
20. V.S. Tripathi and G.T. Yeh, "A Performance Comparison of Scalar, Vector, and Concurrent Vector Computers Including Supercomputers for Modeling Transport of Reactive Contaminants in Groundwater," Water Resour Res., 29, 1819-1823 (1993).

21. C.W. Liu and T.N. Narasimhan, "Redox-Controlled Multispecies Reactive Chemical Transport, 2, Verification and Application," Water Resour. Res., 25, 883-910 (1989).

22. A.R. Felmy, "GMIN: A Computerized Chemical Equilibrium Model using a Constrained Minimization of the Gibbs Free Energy," PNL-7281, Pacific Northwest Laboratory, Richland, Washington (1990).
23. K.S. Pitzer, "Thermal Dynamics of Electrolyte I, Theoretical Basis and General Equations," J. Phys. Chem. 77, 268-277 (1973).

24. M.D. White and W.E. Nichols, MSTS: Multiphase Subsurface Transport Simulator Theory Manual, PNL-8636, Pacific Northwest Laboratory, Richland, Washington (1993).

25. W.E. Nichols and M.D. White, MSTS: Multiphase Subsurface Transport Simulator User's Guide and Reference, PNL-8637, Pacific Northwest Laboratory, Richland, Washington (1993). 